\title{
PEDAGOGICAL FOUNDATIONS OF THE ORGANIZATION OF SPIRITUAL AND MORAL EDUCATION
}

\author{
Karimova Muqaddas Otajonovna ${ }^{1}$ \\ $\mathrm{PhD}$ docent of Fergana State University ${ }^{1}$
}

\author{
Ergashev Umidjon Obidjonovich ${ }^{2}$ \\ $\mathrm{PhD}$ applicant of Fergana Polytechnic \\ Institute $^{2}$
}

Article DOI: https://doi.org/10.36713/epra4480

\begin{abstract}
ANNOTATION
Currently, there is a need for further improvement of moral and spiritual educational work among young people. Without morality, man cannot be a conscious social being. Therefore, moral education occupies a fundamental place in the comprehensive and free development of the individual.

KEY WORDS: moral and spiritual educational, thinkers, education, evasion, spirituality, extinction, students, youth, reason.
\end{abstract}

\section{INTRODUCTION}

The main task of education are moral, freethinking and physical development of the individual, creating opportunities for the full disclosure of its abilities. This was reported by scientists and thinkers of the East such as, "Kutadgu Bilig" Yusuf Khos Hadjib, "Hibbat ul-khakoyik" Ahmad Yugnaki, "Gulistan" Muslihiddin Saadi," Koshusnoma" Unsure Malia of Kaykovus, "the morality of Jaloliddin Davani" of Imam Ismail Bukhari, "Comeu-as Sahih", "al-adab al-mufrad", "At-term" cunnan“," Jawahiri of wisdom "by Abu Nasr forobi," Fazil Shahri", "Treatise on happiness", "memory of past generations" by Abu Rayhan Beruni, " data collection for the study of Jawahiri“," India“, "a Treatise on ethics" by Abu Ali Ibn Sina", It found its expression in such works as " the sage", "Treasure of knowledge", "treatise on ethics".

It is known that from time immemorial, our ancestors paid serious attention to the issues of human education, and this tradition was passed down from generation to generation, improving and enriching the avoidance of new methods. Even now, a person's spirituality depends on education. Ill-bred spirituality finds security, like a building without a Foundation, in which there is no right to comment on this case. Therefore, there is a strong decline in the educational process throughout the country.

Also, the formation of personal spirituality is carried out in all educational institutions together with the family. This means that the family, preschool education, school and other educational institutions are responsible for the formation of moral qualities of the individual. The team of teachers of schools and extracurricular educational institutions (students, class teachers, Directors of spiritual and educational work, children's leaders, etc.) Always has the duty to teach students to lead a life based on universal rules of behavior.

It is desirable that the activities carried out within the framework of moral education of students should be carried out using the following forms and methods:

- "Methods that affect the minds of students" - organization of comics, narratives, lectures and seminars, conversations on spiritual and moral topics, beliefs, demonstration of examples, discussions, meetings, press conferences, competitions. working with press materials, educational and auxiliary literature.

- Moral behavior, methods that contribute to the enrichment of life experience in this regard-official and labor games, competitions and posters, magazines on moral topics, preparation of albums. the solution to the moral problem situations, etc. 


\section{OBJECTIVES}

In the organization of spiritual and moral education, the vision of work, based on the following tools, gives an effective result: personal support for students. the process of forming public opinion, mass media, fiction, demonstration of models, visual weapons, spiritual and moral relations.

In the system of spiritual and moral education, conversations on spiritual and moral topics are of particular importance. Such conversations can be colorful in terms of content. The main task of conducting conversations about moral content is social and moral attitude, which is expressed in teaching students to find a certain attitude,to give a correct assessment of their content in relation to various employees.

Spiritual and moral conversations serve as a means of providing (and strengthening them) information about the moral imagination, understanding, deepening, clarifying knowledge, and new information for students.

\section{METHODOLOGY}

The topic of conversations in the spiritual and moral context is determined by the spirituality of a person-from the General idea of morality, the level of education of students, as well as their interests and needs. In some cases, an event may be the subject of conversation. The interviewer develops his plan or main questions, which he informs the participants of the conversation in advance, determines the speakers on some issues, and prepares the speech for the speech. Appropriate literature is recommended for conducting an interview. For interviews, evidence is collected based on examples described in readers ' biographies and fiction.

The conversation begins with an introductory question from the host, and feedback from the participants is listened to. Based on the comments made, the conversation material will be filled in, summarized and summarized.

The implementation of narratives with the participation of a group or the demonstration of theatrical performances on a particular topic will further increase the power of influence. The conversation should take place in a friendly and positive emotional environment. The interviewer should listen carefully to readers ' responses, encourage those responses that are acceptable, and correct those responses that are inappropriate within the framework of etiquette.

Discussions also play an important role in ensuring the moral and ethical excellence of students. Discussions on spiritual and moral topics serve to give students a correct assessment of a particular situation, about employees, teach them to think about it, as well as to form an image of it. Discussion regulates the course of thought, teaches students to think independently, organize discussions, listen to their partner, put forward their own opinion and defend it figuratively, while at the same time admitting their mistakes.

\section{STATISTICAL DESIGN}

The group will work out 5-6 questions together with class activists for discussion. Participants gain a pre-determined weight. In the course of discussion, the word must be bright and lively. You are not allowed to read the finished text. At the end of the discussion, the opinions are summarized, corrected, and supplemented. Knowing the audience, working with group and class activists, and inviting experts to the discussion will ensure the success and educational impact of the discussion. The discussion is clear and does not require a final decision.

Persuasion is a method of education, one of the main methods of forming the spiritual and moral worldview of the reader. In the method of persuasion, the teacher influences the minds, consent, oratory, and will of the students. form positive qualities of morality and other people in their character through maturation, reduce vices. Protects against negative qualities. Persuasion is a method based on universal values, national traditions and traditions, and a philosophical worldview to which a person is formed based on a deep understanding of the ideology of national independence and its true essence.

Positive personal example is a method that can occupy a special place in the formation of the personality of students, which is the most subjective way to influence a person through the personality.

The content of moral education is manifested primarily in the practical activities of students, in their studies, work, public Affairs, in the nature of their relationships, in the acquisition of methods of interaction, norms of behavior.

Moral education is carried out throughout the life of a person, taking into account age, and the sphere (the sphere of family, friends and associates), which negatively affects the correct orientation of the pupil. The method and methods of moral education have a special feature in the organization of such special work as conducting moral lessons for students. Giving moral knowledge fulfills several educational tasks: it gives a broad idea of the moral frames of human life and culture.

Based on concepts such as moral imagination, vision, reasoning, evaluation, moral values are influenced by ascension, i.e.:

- this will help students observe and enrich their moral experience;

- corrects knowledge gained about ethics from various sources; 
- creates the ground for the moral education of the individual.

When organizing moral knowledge, it is necessary to take into account the age characteristics of students, their personal moral experiences, the level of awareness of moral norms, their relationship with the moral requirements of acquired knowledge in the field of morality.

Educational work is important in the activities carried out within the framework of moral education of students. One of the main and decisive factors in the organization of educational work is the training session, which should be based on the following areas of pedagogy. These include the following:

- class, group, love satining refined ointment;

- class, group dichos.

At present, long-term pedagogical research and work based on the best practices of specialists in this field, the correct orientation of the younger generation to life is one of the most pressing issues of our time, because the purposeful impact on them, first of all, the definition and careful planning of the content of educational hours of future teachers, classification by educational hours, as well as our national and universal values, is an indicator of great success.

"In the world of beauty". The essence of beauty in students, the difference between beauty and hunuk, ethical and aesthetic views, in clothing, in marriage, in work, in morality, in address and speech, in culture, in various fields of art, in poetry, in modern production pay attention to the signs of beauty in areas such as mining.

"A healthy mind in health". Pay attention to the fact that, depending on the age and personal characteristics of students, hygiene standards are observed, beauty, culture and personal health are the key to personal perfection.

"Psychological themes". Students focus on such concepts as conscience, duty, friendship, civil unrest, psychological self-preparation for the upcoming profession, assimilation and selfeducation, etc.

"Environmental education" is a gift of nature from students the responsibility for wealth should be assigned to those who are content with the concepts of preserving, reproducing and protecting their feelings for them to present and future generations.

It should be selected from popular Newspapers and magazines, pamphlets, samples of fiction on pedagogy and parenting, films, diafilms and slides, radio and television programs, topics aimed at educating the perfect person, covering the most important topical issues of our time, as well as life examples for students, for class hours, groups. Then it will be possible to attribute that the creative activity of the students of the class will be provided.

\section{RESULTS}

During such periods, the productive use of technical tools and didactic-reproductive materials will undoubtedly lead to higher positive results of classroom training hours. A class, group, or study hour is an integral part of educational work, and for students, a class, group, or supervisor is a practical and creative activity.

First of all, the teacher must thoroughly prepare for the training that will be conducted in a class, group, or study hour with the selected text. In the process of teaching, the teacher should imbue their goal in the minds of students through various pedagogical influences, such as being an example with impressionable and expressive speech that can fill their hearts. Because school children are tired of the dry Oasis. A class, group, or educational Watch can be taken by a class, group, leader, or class, group, or one of the activists.

When determining the duration of classes, group study hours, it is recommended to take into account the personal characteristics of a teenage student and conduct them on a strict schedule once a week, while observing the rules of hygiene and health protection

\section{SUGGESTIONS}

The structure of the class group training hours. From the point of view of the class structure, group study hours, the content of your own leprosy, the main basic materials on which the plan - summary is compiled, there are 4 parts, namely: :

- introduction;

- main part;

- artistic part;

- it will consist of the final part.

\section{CONCLUSION}

In conclusion, we can say that human perfection is formed in the course of a very complex and continuous process. His upbringing is directly influenced by his parents, school, neighbors, friends, community organizations, the environment, the media, art, literature, nature, and hockey. It is carried out in such a state that through the sphere of their interaction, the education of the individual and the unity of education are ensured.

The main goal of education is to develop and implement effective organizational and pedagogical forms and means based on the rich national, spiritual and historical traditions, customs and universal values of the people.

The main vaztsf of education is the development of the akla's personality, moral, freethinking and physical, creating opportunities to fully reveal their abilities. To do this, you must: preparing young people for free thinking, facilitating their understanding of the meaning of life, the 
formation of self-government and control, a purposeful approach to their personal life, awakening in them a sense of unity of purpose and action:

- to acquaint readers with national and universal values, the rich spiritual heritage of our Motherland, the formation of requirements for the acquisition of cultural and secular knowledge, the qualification of dressing, education and the formation of aesthetic ideas;

- identify the knowledge and creative abilities of each teenager, develop them, introduce them to human activities in various fields;

- the formation of norms of humanitarian etiquette (understanding each other, intolerance of kindness, compassion, racial and national discrimination), the widespread use of educational tools, such as manners of treatment (injustice, deception, slander, intolerance);

- patriotism, secular thinking, long-term relationships with people living in our society-the study of communication, which is always a thing for your people, the state, its protection, respect for your state and the symbols of other States;

- education of respect for the legal social ethics and rules of life, the development of civil and social responsibility that determines the unique aspects of the individual, self-improvement of the country in which he lives, dedication to the sustainable development of humanity, environmental education.

It is also necessary to awaken the student's interest in the study of science, since the qualities of thirst for knowledge are an integral part of moral education. The role of a child in his group is determined from the very beginning by the success of his studies, the attitude of people around him is determined, success in reading raises the moral education of a child to a high level.

\section{REFERENCE}

1. Ziyomukhammedov B and others. Fundamentals of spirituality. Textbook Tashkent,:" National Encyclopedia of Uzbekistan " State scientific publishing house, 2000

2. Atamoratov S. and others. Fundamentals of spirituality. (Text of lectures for higher educational institutions) Tashkent. 2000.

3. Formation of the spirituality of the reader. Tashkent,: "Shark", 2000. 